\title{
Role of Adrenoreceptors in the Implementation of the Stimulator Effect of Serotonin on WPC
}

\section{DS Sveshnikovv ${ }^{1}$, MR Smirnov ${ }^{2 *}$ and AV Kuchuk ${ }^{3}$}

${ }^{1}$ Doctor of Medical Sciences, Associate Professor of the Department of Physiology,

Peoples' Friendship University of Russia (RUDN), Moscow, Russia

${ }^{2}$ Doctor of Biological Sciences, Professor of the Department of Physiology of the

Russian National Research Medical University Named After V.M. N.I. Pirogov (RN-

IMU), Moscow, Russia

${ }^{3}$ Candidate of Medical Sciences, Assistant of the Department of Anatomy of the

RUDN University, Moscow, Russia

*Corresponding Author: MR Smirnov, Doctor of Biological Sciences, Professor of the Department of Physiology of the Russian National Research Medical University

Named After V.M. N.I. Pirogov (RNIMU), Moscow, Russia.
Received: October 04, 2021

Published: January 31, 2022

(C) All rights are reserved by MR Smirnov.,

et al.

\begin{abstract}
We have established that b-adrenergic receptors prevent the development of a stimulatory effect in response to the introduction of serotonin into the body. This action of b-adrenergic receptors is very strong - when serotonin is introduced into the body under conditions of blockade of b-adrenergic receptors, the stimulatory effect of dpk is 5 times greater than in infarcted animals. This is due to the fact that the serotonin introduced into the body activates not only $5 \mathrm{HT}$ receptors of serotonergic neurons and smooth muscles, but also presynaptic 5 - HT receptors of sympathetic nerve endings. Their activation leads to the release of norepinephrine, the latter inhibits contractions of the smooth muscles of the intestine. But the stimulating effect of serotonin on smooth muscle is stronger than the inhibitory effect of norepinephrine.
\end{abstract}

Keywords: Duodenum; Motility; Serotonin Adipate; A- and B-Adrenergic Receptors

\section{Abbreviations}

5HT Receptors - Five Hydroxytryptamine (Serotonin) Receptors, Myogram - Hydrostatic Pressure in the Stomach Cavity, EMG: Electromyogram.

\section{Introduction}

The effect of serotonin on smooth muscle contraction in internal organs is being studied in patient and animal studies. Studies on fasting patients with serotonin have been performed [1]. They recorded the myoelectric activity of the gastrointestinal tract using an electrogastrointestinograph «GASTRON-1» (Russia).
This device provides reception and registration of signals from skin electrodes, as well as storage, processing and documentary presentation of the information received.

an endolymphatic catheter was inserted into the right inguinal lymph node with anesthesia. With the help of a syringe pump «DSh-08», the preparation of serotonin adipinate was infused at a dose of $10 \mathrm{mg}$ once. 1 hour after endolymphatic infusion and after 8 hours the amount of serotonin in the serum of patients was within normal limits. Within 3-7 hours, the patients had a discharge of intestinal gases and the emergence of an independent stool [1]. These authors believe that endolymphatic infusion of serotonin adipate is effective in the fight against postoperative 
intestinal paresis. Allergic reactions and negative side effects to the administration of the drug were not observed.

Other authors [2] in experiments on anesthetized nonsensitized guinea pigs showed that intravenous administration of serotonin dose-dependently increases pulmonary resistance; serotonin causes bronchospasm.

According to the data of experiments performed on guinea pigs [3] and rabbits [4], serotonin increases intestinal motility and passage of the chyme through it. Experiments on rats have shown [5] that the 5HT4 receptor agonist mosapride citrate is able to increase gastric motility when administered intraperitoneally.

However, the possible role of adrenergic receptors in the realization of the stimulatory effect of serotonin on smooth muscles has not been studied. Knowledge of these mechanisms is important for both scientific research and practical medicine, since serotonin is used for therapeutic purposes. It is known that intestinal paresis is a frequent and dangerous complication in elderly and old patients with acute intestinal obstruction.

\section{Materials and Methods}

The experiments were carried out on sexually mature Wistar rats of both sexes, body weight 250-450 g. Studies were carried out on animals on an empty stomach (12 hours after a meal) in a state of the surgical stage of anesthesia (Nembutal $60 \mathrm{mg} / \mathrm{kg}$, intramuscularly). During the experiments, the average duration of which was 2.5 hours, the anesthesia was sufficient and passed without complications. Prior to the experiment, three rats were housed in one type- 4 cage. The contractile activity of the duodenum was judged by the change in the hydrostatic pressure in its cavity (recorded using catheter) and EMG of the longitudinal layer of smooth muscles of the duodenum (recorded using an electrode). The signals from the catheter and the electrode were fed to the BioAmp ML132 amplifier (Adinstruments, Australia), then to the
Maclab 8e analog-to-digital converter (Adinstruments, Australia) connected to the Macintosh Performa 6400/180 computer, where they were registered using the Chart 4.2.3 program.

After checking the data for normality, statistical processing of the data was carried out using the paired Student's test, taking $\mathrm{p}<$ 0.05 as the level of significance.

The effects of serotonin adipate $(0.1 \mathrm{mg} / \mathrm{kg})$ on gastric motor activity were investigated with its intra-arterial administration. The choice of injecting the drug into the artery is justified by the fact that in trial experiments we found an unexpected result intravenous administration of various doses of serotonin (up to 20 $\mathrm{mg} / \mathrm{kg}$ ) did not affect the contraction of the duodenum.

The use of large doses of the mediator in the experiment devalues the results obtained. Possible reflex effects of serotonin were prevented by bilateral transection of the vagus and glossopharyngeal nerves in the neck.

\section{Research Results}

In the first series of experiments, the role of $\alpha$-adrenergic receptors in the realization of the stimulatory effects of serotonin was studied. These studies were performed on 8 animals using doxazosin, a blocker of $\alpha$-adrenergic receptors.

Initially, it was found that this drug did not have a significant effect on intestinal motility, which is consistent with the data of other authors [6].

$10 \mathrm{~min}$ after the injection of doxazosin, the same animals were injected with serotonin, which in all animals caused a more pronounced increase in duodenal contractions than in intact $\alpha$-adrenergic receptors (Table 1 ). The amplitude of slow EMG waves also increased from $0.69 \pm 0.22$ to $1.56 \pm 0.19 \mathrm{mV}(+126 \%$, $\mathrm{p}<0.01)$.

\begin{tabular}{|c|c|c|c|}
\hline Preparation & $\begin{array}{l}\text { Background before } \\
\text { the introduction of the } \\
\text { blocker }\end{array}$ & $\begin{array}{c}\text { The result of the introduction } \\
\text { of the blocker }\end{array}$ & $\begin{array}{l}\text { The result of the introduc- } \\
\text { tion of serotonin against the } \\
\text { background of the action of } \\
\text { the blocker }\end{array}$ \\
\hline $\begin{array}{l}\text { Doxazosin - } \alpha \text {-adrenergic } \\
\text { blocker }\end{array}$ & $10,2 \pm 2,1$ & $10,3 \pm 1,5(0 \%)$ & $\begin{array}{c}15,0 \pm 1,6(+45 \%) \\
P<0.05\end{array}$ \\
\hline Propranolol - $\beta$-adrenoblocator & $11,0 \pm 1,2$ & $8,6 \pm 1,5(-22 \%)$ & $\begin{array}{c}18,9 \pm 2,1(+121 \%) \\
P<0,01\end{array}$ \\
\hline
\end{tabular}

Citation: MR Smirnov., et al. "Role of Adrenoreceptors in the Implementation of the Stimulator Effect of Serotonin on WPC". Acta Scientific Gastrointestinal Disorders 5.2 (2022): 56-60. 
Role of Adrenoreceptors in the Implementation of the Stimulator Effect of Serotonin on WPC

\begin{tabular}{|c|c|c|c|}
\hline Proxodololol - a- and b-blocker & $11,4 \pm 1,6$ & $11,5 \pm 1,2(0 \%)$ & $\begin{array}{c}15,0 \pm 1,4(+31 \%) \\
P<0.05\end{array}$ \\
\hline
\end{tabular}

Table 1: The increase in hydrostatic pressure in the duct cavity ( $\mathrm{mm} \mathrm{Hg}$ and\%) by the introduction of serotonin into the body against the background of the action of adrenergic blockers.

* In intact animals, serotonin adipinate $(0.1 \mathrm{mg} / \mathrm{kg})$ increases the strength of the contractions of WPC by $24 \%$.

An example of the reaction of WPC to the introduction of serotonin in conditions of blockade of $\alpha$ - adrenergic receptors

The results of this series of experiments indicate that intact $\alpha$-adrenergic receptors prevent the development of the stimulatory effect of serotonin.

In the second series of experiments on 10 rats, the role of $\beta$-adrenergic receptors was studied in the development of the stimulatory effects of serotonin. Serotonin was administered against the background of the action of the $\beta$-blocker propranolol. At first, they found out that

propranolol decreased the tone of the intestine - the hydrostatic pressure in its cavity decreased (see Table 1 and Figure 2). However, in $57 \%$ of the animals, despite a decrease in intestinal tone, pronounced peristalsis occurred, as, for example, in this experiment (see Figure 2B). In figure 2B also shows that EMG did not change compared to the background (see Figure 2A). This demonstrates the advantage of recording myogram over EMG.

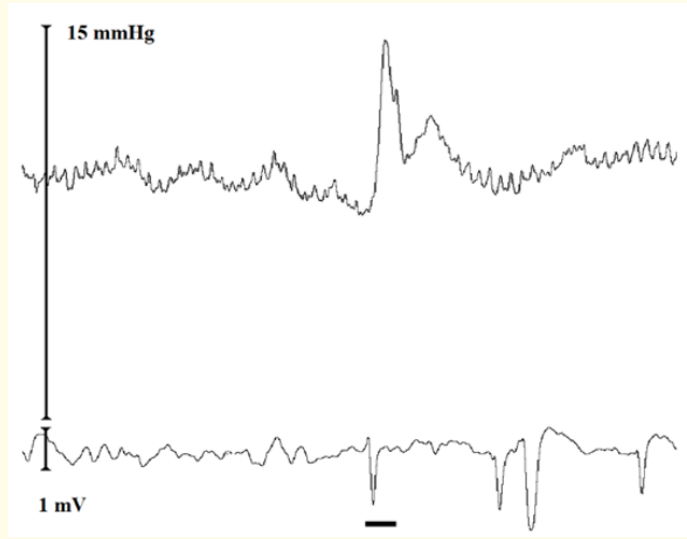

Figure 1: Strengthening the contractions of the duodenum for the introduction of serotonin against the background of the action of the $\alpha$-adrenergic blocker doxazosin: at the top - myogram; below -EMG; bold horizontal line at the bottom - mark of serotonin administration (30 s).
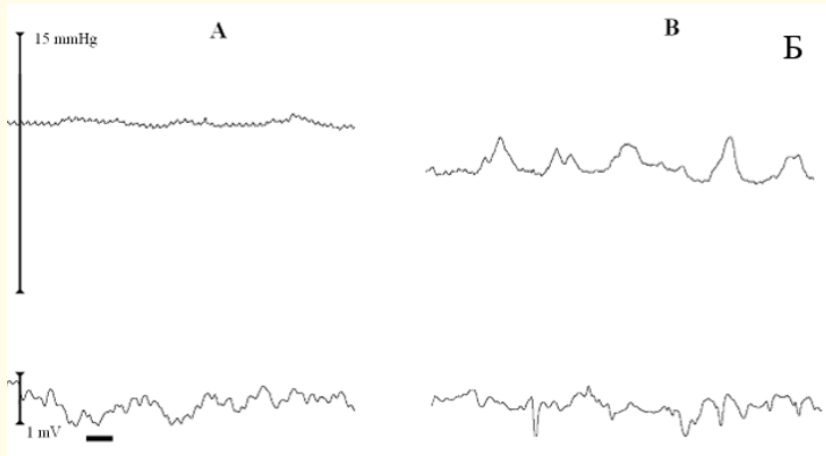

Figure 2: Reactions of the rat duodenum to the administration of $\beta$-blocker propranolol (A) and 10 minutes after its administration (B): at the top - myogram; below -EMG; bold horizontal line at the bottom - mark of propranolol injection

(30 s).

10 minutes after the blockade of $\beta$-adrenergic receptors, all 10 animals were injected with serotonin, which was accompanied by a significant increase in intestinal motility: the hydrostatic pressure in its cavity increased 5 times more than in inactive animals (see Table 1)! The amplitude of slow EMG waves increased from $0.83 \pm$ 0.19 to $1.92 \pm 0.23 \mathrm{mV}(+131.3 \%, \mathrm{p}<0.01)$.

In the third series of experiments, the joint role of $\alpha$ and $\beta$ receptors in the realization of the stimulatory effect of serotonin was investigated. Experiments were performed with proxodolol, a blocker of $\alpha$-and $\beta$-receptors in 9 rats, which did not affect intestinal motility (see Table 1). $10 \mathrm{~min}$ after the injection of proxodolol, the same rats were injected as usually, intra-arterial solution of serotonin $(0.1 \mathrm{mg} / \mathrm{kg})$, which caused stimulatory reactions in all animals (see Table 1 and Figure 3). The amplitude of slow EMG waves increased from $0.69+0.14$ to $1.61+0.13 \mathrm{mV}(+133.3 \%$, $\mathrm{p}<0.01)$. The duration of the reactions was $225.58+24.49 \mathrm{~s}$ and $234.21+16.07 \mathrm{~s}$, respectively, which was somewhat longer than in animals with intact $\alpha$ - and $\beta$-adrenergic receptors. 
Attention should also be paid to the pronounced myogram of the duodenum and «inexpressive» EMG in this experiment (see Figure 3), which indicates a more reliable technique of myography compared to EMG.
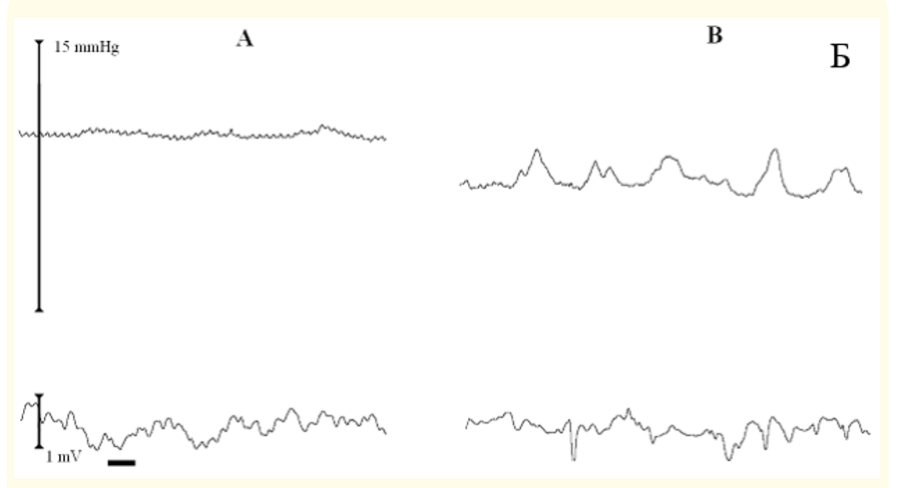

Figure 3: Strengthening the contractions of the duodenum for the introduction of serotonin against the background of the action of proxodolol - a blocker of $\alpha$ - and $\beta$-adrenergic receptors: at the top - myogram, below - EMG, bold horizontal line at the bottom - time stamp (30 s).

The duration of the stimulatory effect on the administration of serotonin under conditions of blockade of $\alpha$-adrenergic receptors was $193+26 s, \beta$-adrenergic receptors $420+56 s$, $\alpha$ - and $\beta$-receptors $226+24 \mathrm{~s}$, in intact animals $185+36 \mathrm{~s}$. The reactions began in all cases within 4-6s after the administration of serotonin.

\section{Discussion of the Results}

The results of our studies showed that when using serotonin to stimulate duodenal motility in patients under conditions of $\beta$-adrenergic receptor blockade, the stimulatory effect would be 5 times greater than in an intact organism.

The question arises - what is the mechanism of weakening the stimulatory effect of serotonin on the duodenum with intact adrenergic receptors? We believe that serotonin injected into the body activates not only 5HT receptors of serotonergic neurons and smooth muscles, but also presynaptic 5HT receptors of sympathetic nerve endings. Their activation leads to the release of norepinephrine, the latter inhibits contractions of the smooth muscles of the intestine. But the stimulating effect of serotonin on smooth muscles is stronger than the inhibitory effect of norepinephrine.
Availability presynaptic 5HT receptors, including those on sympathetic terminals, have been shown by other authors [7-9].

Why is a stronger stimulatory effect of serotonin observed under conditions of $\beta$-adrenergic receptor blockade than with $\alpha$-adrenergic receptor blockade? We believe that the concentration of $\beta$-adrenergic receptors in the duodenum is greater than that of $\alpha$-receptors. The release of norepinephrine from sympathetic endings (under the influence of serotonin) activates $\alpha$ - and $\beta$-adrenergic receptors. Since there are more $\beta$-adrenergic receptors in the duodenum, their activation by norepinephrine secreted by sympathetic endings creates the main obstacle to the direct action of serotonin on the muscles of the duodenum.

According to our data, the tone of the sympathetic nerves for the $\alpha$-receptors of the duodenum is not expressed, or there are very few of them in the duodenum. This is evidenced by the fact that the blockade of $\alpha$-adrenergic receptors does not lead to a change in the strength of contractions of the duodenum (see Table 1 ). The tone of the sympathetic nerve for $\beta$-adrenergic receptors is well expressed, but it is not inhibitory, but stimulatory, as evidenced by the weakening of the tonic contraction of the duodenum after blockade of $\beta$-adrenergic receptors. This fact contradicts the classical and modern concepts of the inhibitory effect of the sympathetic nerve to the contraction of the intestine [10-13]. However, this contradiction is not yet clear.

\section{Conclusion}

The results of our research have shown that the stimulatory effect of the duodenum on the introduction of serotonin into the body under conditions of blockade of $\beta$-adrenergic receptors is 5 times greater than with intact $\beta$-receptors.

\section{Bibliography}

1. Sinenchenko GI., et al. "Endolymphatic infusion of serotonin adipinate in the treatment of postoperative intestinal paresis". Medical Bulletin of the Ministry of Internal Affairs 21.2 (2006) : 21-23.

2. Arreola-Ramírez J., et al. "Modifications of plasma 5-HT concentrations during the allergic bronchoconstriction in guinea pigs". Experimental Lung Research 39.7 (2012): 269-274.

3. Tamura T., et al. "Pharmacological characterization of 5-hydroxytryptamine-induced motor activity (in vitro) in the guinea pig gastric antrum and corpus". European Journal of Pharmacology 308.3 (1996): 315-324. 
4. VI Ovsyannikov and TP Berezina. "Mechanisms of the influence of serotonin on motor activity in the duodenum, jejunum and ileum from awake rabbits. Grown". The Journal of Physiology. they. I. M. Sechenova 8 (2002): 1017-1027.

5. Lee J., et al. "The effects of 5-HT4 receptor agonist, mosapride citrate, on visceral hypersensitivity in a rat model. G. digestive pathology". Digestive Diseases and Sciences 57.6 (2012): 15171524.

6. H Sulyman., et al. "Relation of adrenergic receptors, which have roles in gastroprotective and anti-inflammatory effect of adrenal gland hormones, with cyclooxygenase enzyme levels in rats". The Indian Journal of Physiology and Pharmacology 60.4 (2009): 129-134.

7. Purohit A., et al. "Creation, expression, and characterization of a constitutively active mutant of the human serotonin 5-HT6receptor". Synapse 47.3 (2003): 218-224.

8. MacLean MR and Dempsie Y. "Serotonin and pulmonary hypertension--from bench to bedside". Current Opinion in Pharmacology 9.3 (2009): 281-286.

9. McKenzie C., et al. "Mechanisms involved in the regulation of bovine pulmonary vascular tone by the 5HT1B-receptor". British Journal of Pharmacology 159.1 (2010): 188-200.

10. Kamkin AG and Kamensky AA. "Fundamental and clinical physiology" textbook. M.: «Academy» (2004).

11. Sudakov KV. "Normal physiology” textbook, M.: MIA (2006).

12. Gaiton AK and Hall DE. "Medical physiology" textbook, M.: "Logosphere" (2008).

13. Smirnov VM. "Normal physiology" textbook, M.: Academy (2012).

\section{Assets from publication with us}

- Prompt Acknowledgement after receiving the article

- Thorough Double blinded peer review

- Rapid Publication

- Issue of Publication Certificate

- High visibility of your Published work

Website: www.actascientific.com/

Submit Article: www.actascientific.com/submission.php

Email us: editor@actascientific.com

Contact us: +919182824667

Citation: MR Smirnov., et al. "Role of Adrenoreceptors in the Implementation of the Stimulator Effect of Serotonin on WPC". Acta Scientific Gastrointestinal Disorders 5.2 (2022): 56-60. 